\title{
International Classification of Diseases, Ninth Revision, Clinical Modification
}

National Cancer Institute

\section{Source}

National Cancer Institute. International Classification of Diseases, Ninth Revision, Clinical Modification. NCI Thesaurus. Code C71891.

An extension of the ICD-9 created by the U.S. National Center for Health Statistics so that the system could be used to capture more morbidity data. This extension included a section of procedure codes. 